\title{
Warning Signs in the Era of Unruptured Intracranial Aneurysms: Report on 2 Cases of Fatal Aneurysmal Hemorrhage
}

\author{
Katarzyna Wójtowicz Przemysław Kunert Łukasz Przepiórka Andrzej Marchel \\ Department of Neurosurgery, Medical University of Warsaw, Warsaw, Poland
}

\author{
Keywords \\ Warning signs · Subarachnoid hemorrhage · Unruptured \\ intracranial aneurysm
}

\begin{abstract}
Introduction: The timing of treatment remains unresolved for patients with unruptured intracranial aneurysms (UIAs) and headaches, particularly when the pain is short term, localized, and related to the aneurysm site. We lack evidence to support the notion that when a headache accompanies an aneurysm, it elevates the risk of rupture. Results: We describe 2 cases of fatal subarachnoid hemorrhage in patients with a history of headache and known aneurysms. Both of these patients had good indications for treatment: a young age and an aneurysm $>7 \mathrm{~mm}$, and both were qualified for elective surgery. However, both patients died of fatal aneurysm ruptures before the planned surgery. Conclusion: These cases suggested that treatment should be started as soon as possible, when a UIA is diagnosed based on a shortterm period of severe headaches or when a UIA is observed and then severe headaches appear. There is no straightforward guideline for treatment timing in these patients. However, in this era of UIAs, the significance of sentinel headaches should be reevaluated. Given the incidence of head-
\end{abstract}

karger@karger.com www.karger.com/cee

Karger $\stackrel{\text { ' }}{5}$

BOPEN ACCESS
(C) 2021 The Author(s)

Published by S. Karger AG, Basel

This is an Open Access article licensed under the Creative Commons Attribution-NonCommercial-4.0 International License (CC BY-NC) (http://www.karger.com/Services/OpenAccessLicense), applicable to the online version of the article only. Usage and distribution for commercial purposes requires written permission. aches in the general population and the very low risk of aneurysm rupture, there may be a tendency to neglect the role of headache as a possible warning sign.

(c) 2021 The Author(s)

Published by S. Karger AG, Basel

\section{Introduction}

The timing of treatment remains unresolved for patients with unruptured intracranial aneurysms (UIAs) and headaches, particularly when the pain is short term, localized, and related to the aneurysm site. Therefore, the question remains should the UIA be treated on a nonelective schedule? Currently, we lack evidence to support the notion that when a headache accompanies a UIA, it elevates the risk of aneurysm rupture [1-4]. Consequently, the question remains whether a headache should be considered a warning sign for UIA, and thus, whether it should be assessed as a predictor of UIA rupture. It would be valuable to know when and which aneurysms will rupture. Currently, due to the widespread belief that UIAs "do not cause pain," it is possible that the impact of headaches has been underestimated. Here, we present 2 cases of fatal subarachnoid hemorrhage $(\mathrm{SAH})$ in patients with a history of headache and known aneurysms. 

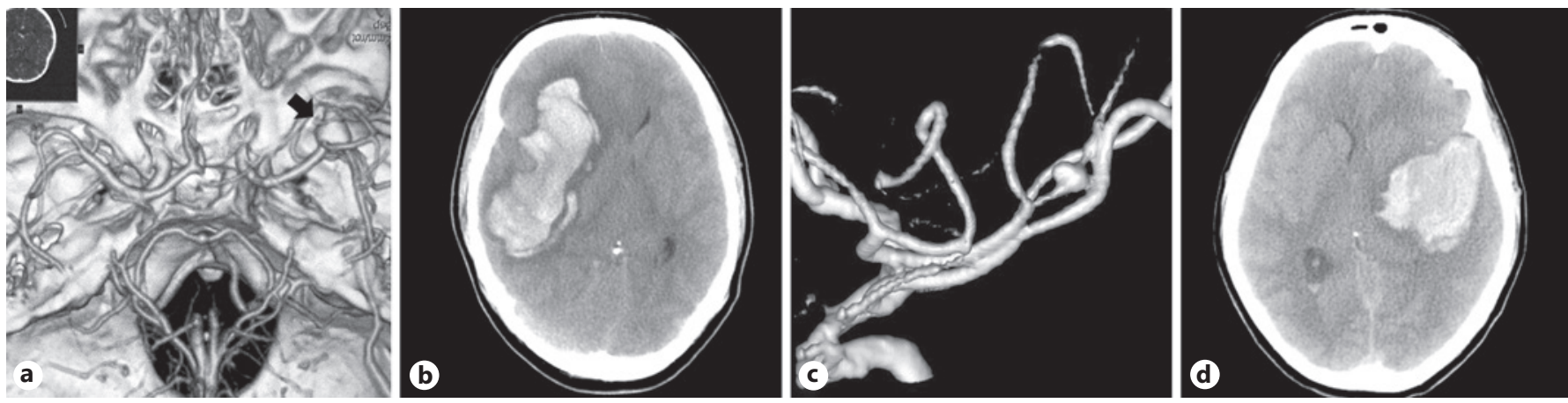

Fig. 1. Brain CT images of 2 patients with UIAs. Case 1: CTA image shows an aneurysm of the right MCA (black arrow) (a); case 1: CT image shows a fronto-temporo-insular intracerebral hematoma (b); case 2: CTA image shows an aneurysm of the left MCA (c); case 2: CT image shows a hematoma in the left temporal lobe, which reaches deep brain structures (d). CT, computed tomography; UIAs, unruptured intracranial aneurysms; CTA, computed tomography angiography; MCA, middle cerebral artery.

\section{Results}

\section{Case 1}

A 43-year-old woman with a known 9-mm aneurysm of the right middle cerebral artery (MCA) (Fig. 1a) was found unresponsive after a sudden increase in headache pain. At admission, she was comatose, with a score of 4 on the Glasgow Coma Scale (GCS) and grade 5 on the World Federation of Neurosurgical Societies (WFNS) grading scale (i.e., pupils equal, dilated, and unresponsive to light). At that stage, she was intubated but did not display respiratory distress. Computed tomography (CT) revealed a large fronto-temporo-insular intracerebral hematoma (ICH) on the right side, which displayed a substantial mass effect (Fig. 1b). She underwent an emergency craniectomy and a partial removal of the hematoma to decrease the intracranial pressure. No improvement was observed after the surgery, and the patient was not qualified for subsequent aneurysm obliteration. The patient died 2 days later.

Before admission, the patient reported a 4-week history of headaches in the right temporal area, sometimes with nausea. This was the indication for performing CT, magnetic resonance imaging, and computed tomography angiography. There were no signs of intracranial hemorrhage in the initial neuroimaging studies, and there was no loss of consciousness or meningeal symptoms during this period. After the UIA diagnosis, active treatment was offered, because she was young and a smoker, the aneurysm was multi-lobulated, and its diameter exceeded 7 $\mathrm{mm}$. She was qualified for semi-elective surgery at the soonest available date (2 weeks after the UIA diagnosis) at our department. She had also been informed about the possibility of treatment in other neurosurgical departments. Seven days before the planned surgery, the aneurysm ruptured.

\section{Case 2}

A 26-year-old woman was admitted to our department after an SAH. She had a large ICH $(56 \times 48 \mathrm{~mm})$ in the left temporal lobe that reached deep brain structures (Fig. 1d). At admission, she was deeply unconscious $(\mathrm{GCS}=3$; WFNS $=$ grade 5$)$, with respiratory failure that required mechanical ventilation. Due to the large mass effect, she underwent surgery immediately after admission. The ICH was removed, and the left middle cerebral artery aneurysm was clipped. There was no improvement after surgery, and she died during the second day in the hospital.

The aneurysm was diagnosed with computed tomography angiography (Fig. 1c) 2 months before the rupture. The patient was qualified for elective surgery at another center. The appointed date of surgery was 2.5 months after the UIA diagnosis. The indication for the neuroimaging studies was intermittent headaches that occurred over the past 1.5 years. The headaches were moderate, rarely severe, and localized on the left side of the head. There was no history of a previous SAH.

\section{Discussion}

Several decades ago, warning signs of aneurysm rupture were widely investigated in patients who had experienced an SAH. Those studies were motivated by the conviction that treating an aneurysm before rupture 
would lead to a more favorable outcome [5]. Prodromal events were observed in $48 \%$ of patients in a series described by Okawara [5] and in $20 \%$ of patients in a cooperative study by Bassi et al. [6]. These warning signs appeared, on average, 2-3 weeks before a major hemorrhage [5].

There are 3 proposed mechanisms that can give rise to warning signs: a sentinel leak, a mass effect due to aneurysm expansion, and ischemic events. The most frequent symptom is headache, which may be general $(25 \%)$ or localized $(18 \%)$. General headaches are assumed to be caused by a minor aneurysmal hemorrhage $[7,8]$. A warning leak prior to the $\mathrm{SAH}$ was observed in $36 \%$ of patients in the prospective series by Sørensen et al. [9]. However, the concept of warning leaks was questioned in subsequent prospective studies [10]. Nevertheless, a number of patients have had sentinel headaches, which in retrospect, comprised a clear warning sign. An abrupt, severe, or thunderclap headache might also be a warning sign. Regrettably, these headaches are frequently nonspecific, poorly characterized, and mistaken for migraine. Lebedeva et al. [11] found that $62 \%$ of patients complained of headaches during the year prior to aneurysm rupture, compared to $33 \%$ in a group of healthy volunteers. The most frequent (39\%) type of headache was migraine without an aura [11]. Gambhir et al. [12] retrospectively found that sentinel headaches occurred days to months before major bleeding in $38 \%$ of patients who experienced a fatal SAH. Additionally, Gilard et al. [13] suggested that in addition to a thunderclap headache or a new headache, a modification in a common headache could be a sign of aneurysmal instability. Those studies indicated that for some patients with headaches, the origin of the headache was recognized too late. It is commonly mentioned in the scientific neurosurgical literature that a warning sign precedes aneurysmal rupture, but none has offered any real-life recommendations or evidence [14]. In future, aneurysm-targeted specific magnetic resonance imaging sequences might assist in diagnosing sentinel headaches [14-18].

Currently, the majority of UIAs are diagnosed based on unrelated signs in noninvasive studies. Nevertheless, a common indication for neuroimaging is headache, which can potentially be a warning sign [1]. UIAs can be treated surgically or endovascularly; however, based on current knowledge, observation is probably the best treatment choice for many patients, particularly for those with aneurysms $<7 \mathrm{~mm}$. A previous autopsy series indicated that the majority of aneurysms never bleed throughout the

Warning Signs for Aneurysm Rupture lifespan of the patient [19]. Furthermore, the risk associated with the burden of global treatment was comparable to the risk associated with the natural history of UIAs. Consequently, detailed studies have aimed to identify subgroups of aneurysms that were more prone to rupture and thus could justify a proposed treatment. The first algorithms designed to facilitate decision-making on UIAs depended on various clinical and radiological factors. Despite the fact that cranial nerve palsy with sudden onset is considered a warning sign that indicates the need for early aneurysm treatment, currently, the sentinel headache is not included among the warning factors $[1,3,20]$. In the present case study, we aimed to add to the pool of data that might, in future, contribute to updating recommendations. Additionally, we set out to highlight diagnostic importance of warning signs, as initial misdiagnosis of SAH worsens prognosis [21,22].

Both of our patients had favorable indications for treatment: they were both young and the aneurysms were $>7 \mathrm{~mm}$. Both were qualified for elective surgery and were scheduled for hospitalization. There was no need for urgent surgery due to the lack of SAH. However, our findings suggested that when a UIA is diagnosed based on a short period of severe headaches or when a UIA is observed and then severe headaches appear, treatment should be started as soon as possible. Moreover, it has been reported that once the aneurysm has ruptured, a history of sentinel headache does not have prognostic significance, in terms of clinical course or functional outcome [23]. Thus, patients with known UIAs who refuse treatment should be informed about the significance of the warning signs. Theoretically, when the headache reported by the patient is considered a warning sign, according to the calculations mentioned above, treatment should be performed within 1 week of the onset of pain. Although there is no straightforward guideline for the timing of treatment, in this era of UIAs, the significance of sentinel headache should be reevaluated.

\section{Conclusion}

Given the incidence of headaches in the general population and the very low risk of aneurysm ruptures, there may be a tendency to neglect the role of headache as a potential warning sign in UIAs. Due to the frequency of UIAs observed currently, the significance of a headache as a warning sign should be investigated and discussed again. 


\section{Statement of Ethics}

This retrospective review of patient data did not require ethical approval in accordance with local guidelines. Written informed consent was obtained from the next of kin of the patient for publication of the details of their medical case and any accompanying images.

\section{Conflict of Interest Statement}

The authors declare no conflicts of interest.

\section{Funding Sources}

This research received no external funding.

\section{Author Contributions}

Conceptualization: P.K. and K.W.; methodology: P.K. and K.W.; formal analysis: Ł.P and A.M.; writing - original draft preparation: P.K. and K.W.; writing - review and editing: K.W. and Ł.P.; visualization: A.M.; supervision: A.M. and Ł.P.; and project administration: Ł.P. All authors have read and agreed for publication of the current version of the manuscript.

\section{References}

1 Thompson BG, Brown RD, Amin-Hanjani S, Broderick JP, Cockroft KM, Connolly ES, et al. Guidelines for the management of patients with unruptured intracranial aneurysms: a guideline for healthcare professionals from the American Heart Association/American Stroke Association. Stroke. 2015 Aug;46(8): 2368-400.

2 Backes D, Vergouwen MD, Tiel Groenestege AT, Bor AS, Velthuis BK, Greving JP, et al. PHASES score for prediction of intracranial aneurysm growth. Stroke. 2015 May;46(5): $1221-6$.

3 Greving JP, Wermer MJ, Brown RD, Morita A, Juvela S, Yonekura M, et al. Development of the PHASES score for prediction of risk of rupture of intracranial aneurysms: a pooled analysis of six prospective cohort studies. Lancet Neurol. 2014 Jan;13(1):59-66.

4 Juvela S. Treatment scoring of unruptured intracranial aneurysms. Stroke. 2019 Sep 1; 50(9):2344-50.

5 Okawara $\mathrm{SH}$. Warning signs prior to rupture of an intracranial aneurysm. J Neurosurg. 1973 May;38(5):575-80.

6 Bassi P, Bandera R, Loiero M, Tognoni G, Mangoni A. Warning signs in subarachnoid hemorrhage: a cooperative study. Acta Neurol Scand. 1991 Oct;84(4):277-81.

7 Ishii D, Nakagawa D, Zanaty M, Roa JA, Al Kasab S, Shaban A, et al. Quantitative susceptibility mapping and vessel wall imaging as screening tools to detect microbleed in sentinel headache. J Clin Med. 2020 Apr 1;9(4).

8 Nakagawa D, Cushing C, Nagahama Y, Allan L, Hasan D. Quantitative susceptibility mapping as a possible tool to radiographically diagnose sentinel headache associated with intracranial aneurysm: case report. World Neurosurg. 2017 Jul;103:954.e1-4.
9 Sørensen P, Andersen BB, Astrup J. [Warning bleedings prior to subarachnoid hemorrhage from intracranial, sacculate aneurysms. A consecutive, prospective study]. Ugeskr Laeger. 1992 Apr 6;154(15):1027-32.

10 Linn FH, Wijdicks EF, van der Graaf Y, Weerdesteyn-van Vliet FA, Bartelds AI, van Gijn J. Prospective study of sentinel headache in aneurysmal subarachnoid haemorrhage. Lancet. 1994 Aug 27;344(8922):590-3.

11 Lebedeva ER, Gurary NM, Sakovich VP, Olesen J. Migraine before rupture of intracranial aneurysms. J Headache Pain. 2013 Feb 20;14: 15.

12 Gambhir S, O'Grady G, Koelmeyer T. Clinical lessons and risk factors from 403 fatal cases of subarachnoid haemorrhage. J Clin Neurosci. 2009 Jul;16(7):921-4.

13 Gilard V, Grangeon L, Guegan-Massardier E, Sallansonnet-Froment M, Maltête D, Derrey $\mathrm{S}$, et al. Headache changes prior to aneurysmal rupture: a symptom of unruptured aneurysm? Neurochirurgie. 2016 Oct;62(5):241-4.

14 Fu Q, Wang Y, Zhang Y, Zhang Y, Guo X, Xu $\mathrm{H}$, et al. Qualitative and quantitative wall enhancement on magnetic resonance imaging is associated with symptoms of unruptured intracranial aneurysms. Stroke. 2021 Jan 1; 52(1):213-22.

15 Fu Q, Guan S, Liu C, Wang K, Cheng J. Clinical significance of circumferential aneurysmal wall enhancement in symptomatic patients with unruptured intracranial aneurysms: a high-resolution MRI study. Clin Neuroradiol. 2018 Dec;28(4):509-14.

16 Wan Z, Meng H, Xu N, Liu T, Chen Z, Sun Y, et al. Clinical characteristics associated with sentinel headache in patients with unruptured intracranial aneurysms. Interv Neuroradiol. 2020 Nov 4:1591019920971977.
17 Nakagawa D, Kudo K, Awe O, Zanaty M, Nagahama Y, Cushing C, et al. Detection of microbleeds associated with sentinel headache using MRI quantitative susceptibility mapping: pilot study. J Neurosurg. 2018 May $1: 1-7$.

18 Zhu C, Wang X, Eisenmenger L, Shi Z, Degnan A, Tian B, et al. Wall enhancement on black-blood MRI is independently associated with symptomatic status of unruptured intracranial saccular aneurysm. Eur Radiol. 2020 Dec;30(12):6413-20.

19 Rinkel GJ, Djibuti M, Algra A, van Gijn J. Prevalence and risk of rupture of intracranial aneurysms: a systematic review. Stroke. 1998 Jan;29(1):251-6.

20 Chalouhi N, Dumont AS, Randazzo C, Tjoumakaris S, Gonzalez LF, Rosenwasser R, et al. Management of incidentally discovered intracranial vascular abnormalities. Neurosurg Focus. 2011 Dec;31(6):E1.

21 Kowalski RG, Claassen J, Kreiter KT, Bates JE, Ostapkovich ND, Connolly ES, et al. Initial misdiagnosis and outcome after subarachnoid hemorrhage. JAMA. 2004 Feb 18;291(7): 866-9.

22 Ois A, Vivas E, Figueras-Aguirre G, Guimaraens L, Cuadrado-Godia E, Avellaneda C, et al. Misdiagnosis worsens prognosis in subarachnoid hemorrhage with good Hunt and Hess Score. Stroke. 2019 Nov;50(11):3072-6.

23 Viarasilpa T, Ghosh P, Gidwani S, Lantigua H, De Marchis GM, Panyavachiraporn N, et al. Prognostic significance of sentinel headache preceding aneurysmal subarachnoid hemorrhage. World Neurosurg. 2020 Jul;139: e672-6. 